\title{
A Conceptualisation of Crowd Knowledge
}

\author{
Till Blesik $^{1} \cdot$ Markus Bick $^{1}$ (D) Tyge-F. Kummer $^{2}$ \\ Accepted: 10 June 2021 / Published online: 5 August 2021 \\ (C) The Author(s) 2021
}

\begin{abstract}
Propelled by digitalisation, crowd knowledge (CK) has gained popularity alongside a plurality of related crowd-based concepts (crowdsourcing, wisdom of crowds and collective intelligence), resulting in an inconsistent understanding of the terms and their application. Based on a structured literature review, we conceptualise CK and develop a formal definition, which is then evaluated using knowledge artefacts on different crowd-related platforms and differentiation criteria in relation to participants, context, purpose and process. The paper posits that CK is conceptually different from related concepts, due to its dynamic nature and its instantiation in the form of a CK knowledge artefact which requires a specific context and a unique knowledge-creation process. Furthermore, we discuss how the concept of CK and its associated artefact relates to established knowledge management concepts such as knowledge assets and the flow of $\mathrm{CK}$ in the epistemological differentiation of knowledge into tacit and explicit elements. The article contributes to the formal conceptualisation of crowd-based concepts and therefore improves understanding of existing implementations and supports the prudent design of future systems.
\end{abstract}

Keywords Crowd knowledge $\cdot$ Crowd sourcing $\cdot$ Conceptual definition $\cdot$ Literature review

\section{Introduction}

The aim of this paper is to conceptualise crowd knowledge (CK) by exploring characteristics that distributed, fluid crowds dictate, and by linking crowd-based processes. CK is often integrated in web applications (de Souza, Campos, \& de Maia, 2014a; Estellés-Arolas \& González-Ladrón-deGuevara, 2012; Herzog \& Claunch, 1997; Shirazi et al., 2010) or researchers use the term (Brynjolfsson et al., 2016; Jyh-Ren et al., 2010), but its distinction from other crowdbased concepts is not well understood, and it is not holistically conceptualised, thus hindering theoretical advances and practical interoperability. However, a clear conceptualisation thereof would improve related systems and the instantiation of knowledge within these systems. In addition, it would support CK implementations and enable semantic interoperability.

Markus Bick

mbick@escp.eu

1 ESCP Business School, Campus Berlin, Heubnerwg 8 - 10, D-14059 BerlinGermany

2 QUT Business School, Queensland University of Technology, 2 George St, Brisbane, QLD 4000, Australia
Analysing the term etymologically reveals a common structure amongst crowd-based concepts such as crowdsourcing (Estellés-Arolas \& González-Ladrón-deGuevara, 2012). First, 'crowd' refers to people that participate. Second, 'knowledge' refers to the processing of knowledge, and therefore knowledge management. 'Crowd knowledge' means knowledge as the collective possession of a group of people, i.e. the crowd, but it is most famously understood by Polanyi (2005) as an individual possession divided into tacit and explicit knowledge, where the former cannot be explicated and is therefore not accessible for anyone but the possessing person.

Opposing the personal character of knowledge, Wittgenstein and Anscombe (1958) emphasise that all knowledge is collective, thus founding a social theory thereof (Bloor, 1983). By resolving some of the contradictions, Tsoukas and Vladimirou (2001) fused both perspectives to conceptualise organisational knowledge as a typological child of CK, arguing that a theoretical understanding of both organisation and knowledge is necessary to grasp the conjoint concept.

While organisational knowledge constitutes a tangible instantiation for $\mathrm{CK}$, with members of the organisation being the crowd, its confinement to organisational environments impedes the need to explain the characteristics of CK on a generic level. Although the dynamic character of knowledge highlighted by Davenport (1998) is considered, an 
organisation provides an effective static context in which knowledge can flourish and related actions take place.

Simply stating that CK is knowledge created by a crowd is as true as it is obvious, but it does not provide any further insights into or understanding of its characteristics. CK gained popularity as technology developed, allowing the ability to connect people far apart and to form dynamic and irregular crowds, thus leading to the opposite of a static context. In contrast to organisational contexts, crowds are typically dynamic, and while they may contain regular contributors, new knowledge creators and users can join at any time (Howe, 2006; Lukyanenko et al., 2017).

Without an all-encapsulating context, CK must instantiate an artefact that incorporates its original environment, in the form of a technical implementation that provides a data structure through which to represent the respective knowledge and to store all related features. Considering the dynamic of crowds and the strong affiliation of CK and information technology, processual issues like storing, retrieving, transmitting and sharing can become pivotal, even though these knowledge-as-information aspects were omitted by Tsoukas and Vladimirou (2001).

Comparing existing theoretical foundations for crowds, in the sense of dynamically formed compositions of people based on digitalisation, and knowledge, the latter has matured, while crowds are immature. About 100 years ago, Le Bon assumed that the crowd is generally primitive and intellectually inferior to the individual (Le Bon, 1897), and a common socio-psychological view was that if not directed and controlled, no good or value could come of it. Since then, a lot has changed, and in terms of digitalisation, crowds are nowadays seen as a source of cheap labour (Howe, 2006), wisdom (Surowiecki, 2005), intelligence (Bonabeau, 2009) and knowledge (de Souza, Campos, \& de Maia, 2014a; de Souza, Campos, \& Maia, 2014b).

Numerous collaborative web services that encourage CK exist, and the semantic web specifically aims at relating objects or entire web services to each other, in order to create networks of knowledge (Gong, 2017; Mcllraith et al., 2001). Technologies and methods such as blockchain, artificial intelligence or big data (Hota et al., 2015) certainly integrate these knowledge artefacts, but without a clear understanding and conceptualisation, truly interoperable knowledge artefacts cannot be developed, and instead of integrative, interoperable solutions that drive knowledge management forward, isolated and short-lived solutions form. The need for further understanding of applicable theories and a precise definition of CK was called for by Pawlowski et al. (2014) and by Prpić and Shukla (2014) for their crowd capital theory.

We argue that knowledge is well-theorised, and so the inconsistent use and vague conceptualisation of CK has two roots: first, current crowd-based approaches flourish on increased technology penetration and have developed alongside digitalisation, albeit without clearly aligning pre-digitalisation concepts, thus resulting in ambiguity. Second, there is poor understanding of the specific characteristics imposed by crowds in times of digitalisation.

The research objectives of this article are to:

1. Create a conceptual CK definition and untangle it from other crowd-based concepts.

2. Evaluate the definition, using real-world examples.

The paper is structured as follows. First, it presents a summary of traditional knowledge management and existing crowd-based concepts and exposes entanglement issues. Second, a structured literature analysis is applied leading to a conceptual definition of $\mathrm{CK}$ and its demonstration of applicability. Then, the definition and its implications are discussed, set in relation to other concepts and then integrated in the established body of theory. Lastly, a conclusion summarises our contribution.

\section{Concepts Relating to Crowd Knowledge}

In this section, we provide an overview of the related literature. Concepts in relation to traditional knowledge management and crowd-specific concepts are discussed in turn.

\section{1 (Traditional) Knowledge Management Concepts}

There are various definitions out there trying to define knowledge and, thus, knowledge management. Most commonly, the so-called 'data-information-knowledge-wisdom' (DIKW) pyramid is used to explain corresponding hierarchies and subsequently how context makes the difference between information and knowledge, i.e. "Information must be put into context to become knowledge" (Garvin \& Berkman, 1995). In order to move from information to knowledge, the former must be processed, and specifically, judgement must be exercised (Bell, 1976).

Thus, knowledge constitutes the second-highest layer in this pyramid and is understood as 'know-how' or 'skill', or alternatively as the ability to merge experience with information (Bates, 2005; Rowley, 2007). Recent research criticises the DIKW pyramid on a technical level, for containing logical errors and methodological flaws (Frické, 2009), and on a content-based level, for failing to represent reality (Jennex \& Bartczak, 2013).

To resolve the technical points of criticism, a propositional account of knowledge is suggested (Frické, 2009). In this model, knowledge describes 'knowing-that' instead of 'know-how', which makes knowledge and information synonymous. Consequently, knowledge can be articulated and is recordable. Considering Nonaka's (1994) epistemological 
dimension, this is categorised as 'explicit knowledge', thereby diminishing the concept's philosophical depth and manifoldness.

Including knowledge management as the extraction of reality in a revised knowledge pyramid (Fig. 1) is a possible way of solving the content-based issue (Jennex \& Bartczak, 2013). The revised approach takes knowledge management-related processes into account instead of only considering hierarchical relationships in the DIKW. In current digital environments, knowledge records are necessarily connected to and processed by an information system, thereby justifying recognition in the revised model. As shown in Fig. 1, the traditional hierarchical illustration of knowledge is rather basic and does not sufficiently include today's complex digital environments. The revised model includes social networks as loose depictions of any method that is used to transfer the contained hierarchical elements between users. Jennex and Bartczak's (2013) revised model furthermore acknowledges that the same information can be analysed and restructured in different contexts, leading to an inverted pyramid. Accordingly, organisational learning, organisational memory and organisational knowledge management draw from a generic foundation and apply filters to identify the most relevant knowledge, e.g. for decision support, in their (organisational) contexts. This is a fundamental difference in relation to the traditional model, and it provides a theoretical basis from which to approach the research objectives of this paper, as it implies context-specific knowledge artefacts.

In line with increasing digital penetration, the value of knowledge became evident, and knowledge management was acknowledged as an essential factor for efficiency (Wiig, 1997), thus leading to its integration into organisational capability theories (Gold et al., 2001). Specialised IT artefacts for knowledge management accommodate and reinforce the importance of knowledge in digital environments with distributed participants (Butler et al., 2008). One prominent exponent is the organisational memory (system), which follows the metaphor of a human memory (Lehner \& Maier, 2000), i.e. a system (memory) establishing the cognitive structures of information-storing and -processing for the entire organisation (Hedberg, 1981). This rather declarative understanding of knowledge stands in contrast to the general understanding of crowd knowledge. While the potency of knowledge and its beneficial synergies with crowd mechanisms is often analysed and described in relation to organisations, its application does not require an organisational structure and spreads throughout disciplines.

\subsection{Crowdsourcing, Wisdom of the Crowd and Crowd Intelligence}

As there is not yet a clear conceptualisation of CK (section 1), researchers synonymously, or at least without clear distinction or reasoning, use the similar terms 'crowd knowledge' (CK), 'crowdsourcing' (CS), 'collective intelligence' (CI) and 'wisdom of crowds' (WoC). The entanglement of these terms adds further complexity; for example, knowledge is listed by Simmons et al. (2011) as one of four conditions that must be met for a wise crowd, whilst Malone et al. (2009) understand $\mathrm{CI}$ as an overarching term incorporating CS, WoC and more. Also, Saxton et al. (2013) talk about a CS model that taps the $\mathrm{CI}$ and harnesses the crowd, and to complete the muddle, CK is identified by Erickson et al. (2012) as one of three key themes of the crowd from the perspective of organisational needs.

As various terms are used without a definition, it is difficult for researchers to build upon each other's work, resulting in little clarity and many comparability issues - all ultimately hindering theoretical advances. Besides, practitioners might struggle to select the right approach for their requirements and correctly implement it thereafter, as characteristics and related guidelines are not clearly attributable.

'Crowdsourcing' is a frequently used term. It was coined in a Wired article by Howe (2006) and refers to internet-
Fig. 1 Traditional knowledge management concepts

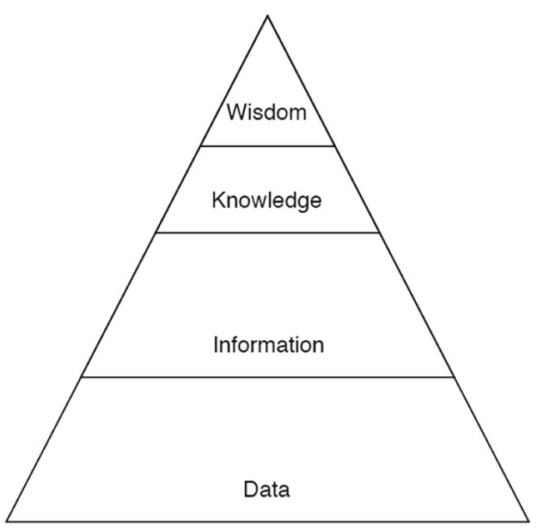

DIKW pyramid (Bell, 1976)

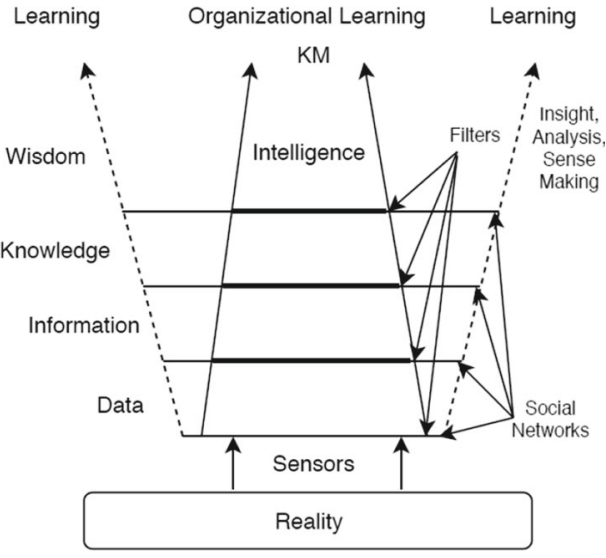

Revised knowledge pyramid Jennex \& Bartczak's (2013) 
mediated collaborative processes induced by outsourcing an activity to an undefined group of people through an open call. Howe sees increasing internet penetration as the main reason for the rise of CS and highlights in his definition the internet as a transmission medium for an online call, with the online crowd responding to that call. On the one hand, the extensive amount of CS literature in various fields highlights its adaptability and popularity, but it also emphasises that there is no clear definition. Estellés-Arolas and González-Ladrón-deGuevara (2012) examined 36 definitions and revealed the crowd, the initiator and the process as defining elements. Crowdsourcing's adaptability leads to a broad range of applications, and most of the respective definitions focus on a specific context, resulting in an often undifferentiated utilisation of terms by the scientific community (Estellés-Arolas \& González-Ladrón-de-Guevara, 2012) and a wide range of applied methods, theories and perspectives (Ayaburi et al., 2020, Zhao \& Zhu, 2014).

The ' $\mathrm{WoC}$ ' is the second extensively used term and was introduced by Surowiecki in "The Wisdom of Crowds." It is based on a journalistic aggregation of case studies and anecdotes of large groups in some way outperforming experts (Surowiecki, 2005). This concept was first noted by Galton (1907), who observed that the crowd judged the weight of cattle better than the 'experts'. In his framework, Surowiecki (2005) formulates four prerequisites for what he terms a "wise" crowd: cognitive diversity, independence, decentralisation and aggregation.

'Collective intelligence', in its current form, was theorised by Lévy (1997) and is defined as the process of sharing, editing and assessing information and other crowd members' findings, in order to understand the world better. From the more recent perspective of "Wikinomics", Tapscott (2011) decompose CI into the four dimensions of openness, peer production, sharing and acting globally.

While the crowd is the element common to all three concepts, there are clear distinctions. Crowdsourcing is focused on solving problems using technology support, especially the internet, and most of its definitions and applications rely explicitly on internet technologies and outsourcing (EstellésArolas \& González-Ladrón-de-Guevara, 2012).

Neither WoC nor CI specifies the transmission medium or technology used. The former aims at combining anonymously created data not influencing each other but which could be implemented in an organisation without any technological information systems. Good examples of this kind of in-person, low-tech implementation would be citizen juries or openforum discussions (Saxton et al., 2013). While operational implementation is similar, CI promotes the continuous process of peer revision, collection and collaboration, which is contra to anonymity. Furthermore, the two elements aim primarily at organisational improvement, though CI pursues a better understanding of the world (Lévy, 1997).

\section{Development of the CK Definition and Demonstration of its Applicability}

Pawlowski et al. (2014) explain the importance of clear conceptual definitions for progress in the field of (social) knowledge environments. As a reaction to the lack of comprehensive guidelines for developing such definitions, they provide concrete steps for researchers in four distinct phases. We apply this guideline in the following, to conceptualise and define CK.

\subsection{Stage 1: Information Search, Selection and Preparation to Identify Potential Attributes}

The core element in our endeavour to form a cohesive definition is a systematic literature review (Webster \& Watson, 2002). The methodological approach to identify relevant research papers was based on Piccoli and Ives (2005). Following this approach, we selected papers through a systematic database search, and we identified them in four steps. First, we acknowledged relevant papers in the Association for Information Systems' Senior Scholars' Basket of Journals (AIS, 2011). This step allowed us to determine and test keywords to ensure that relevant publications from these outlets would be included in our database search. Next, we applied the search terms and pinpointed papers based on keyword searches in journal databases. Third, we selected papers that seemed to provide an added value regarding the first research objectives of this paper, by examining the title and abstract of the relevant papers. Finally, we analysed the selected contributions in detail, in order to examine if they provided value for the in-depth literature review.

We used a total of seven comprehensive publication databases and scientific search engines covering key journals not only on the IS discipline, but also a wide range of other fields. We searched the literature by searching the title, abstract, keywords and text of all papers within the database and search engines.

For the search, the expressions 'crowd knowledge' and ('crowd' AND 'knowledge') were used (Table 1). Where possible, key sensitivity was deactivated; otherwise, the search was performed a second time with capitalised expressions. While we did not restrict the timeframe in the literature search, the search results revealed that prior to 1997, the amount of publications drops substantially to 1 or fewer results per year.

Table 2 provides an overview of the results. Google Scholar produced by far the most hits, which is to be expected, as it is a meta search engine. As a result, overlaps in the search results exist. In total, the search produced 444 hits, which were condensed to 101 publications that were analysed in detail, resulting in 11 remaining papers. Out of these, only two papers (Kern, 2013; Pawlowski et al., 2014) define CK explicitly, while the remaining nine articles use the CK term only 
Table 1 Search criteria and literature search approach

\begin{tabular}{ll}
\hline Criteria & Literature search approach \\
\hline Databases/ scientific search engines & Google Scholar, EBSCO, ACM, IEEE, ScienceDirect, Sage, Emerald \\
Search fields & Title, Abstract, Keywords, Text \\
Search terms & "Crowd Knowledge", "Crowd” AND "Knowledge" \\
Search period & Papers published until May 2020 \\
\hline
\end{tabular}

implicitly. In addition, we observe that $\mathrm{CK}$ is used inconsistently depending on the context and the selected research object, thus indicating the need for a general CK conceptualisation and suggesting that the knowledge artefact is highly relevant for the CK application in a specific context. Table 3 summarises the results of the information search, including the definition of the term, the context and the research object of the study. The 11 identified papers will be used in the following to conceptualise CK.

\subsection{Stage 2: Organise Potential Attributes}

From the previously identified articles, we extract explicit definitions and specific descriptions of CK, applying Tatarkiewicz's (2012) approach for definition creation. In his work, he defined the concept 'art' by collecting existing definitions, extracting all properties possessed only by art and then merging them into one definition to unify all examples (Tatarkiewicz, 2012). This approach has already been used to form an integrated CS definition (Estellés-Arolas \& GonzálezLadrón-de-Guevara, 2012). As our goal is to clarify the entanglement of CK and further terms for crowd-based concepts, we first extract common elements among CK meanings, to form a united definition. To ensure the reliability of the extracted elements, we use a structured coding process, whereby the definitions are independently coded by two coders, following which the created codes are exchanged and the definitions are coded again with each other's codes. In a last step, the codes are discussed and merged, and a condensed set of the most suitable codes is agreed on, thereby constituting the most common elements.
The independent coding of two coders resulted in 18 codes, three of which were identical and two only slightly differently worded. Next, the definitions were coded again with exchanged codes, resulting in 39 matching elements and five coded differently, indicating high intercoder reliability of $88.64 \%$. After further discussion, and merging based on the intended meaning of the created codes, 13 characteristics emerged, establishing possible differentiation criteria Tatarkiewicz (2012) calls these criteria "differentia specifica" - which were analysed further and grouped to build categories and subordinate characteristics, resulting in four characteristics for CK: 1. Participation, 2. Context, 3. Purpose and 4. Process. The different characteristics and their manifestations are presented in Table 4.

\subsection{Stage 3: Development of a Preliminary Definition}

The identified common elements establish necessary attributes for CK. In this step, we compare how these elements are distinguished among the introduced crowd-based concepts. However, in order to determine where the distinction is most relevant, we apply particular emphasis to the concept that overlaps most with CK. To that end, we use the Lucene similarity score (Lucence, 2017), based on our initial search results with 444 hits. By calculating the Lucene score with queries containing the names of relevant concepts within the repository, we can rank these concepts based on their similarity score to scientific CK articles. The Lucence score and our calculation are described in Appendix A. The results suggest that CS has the highest Lucene score, followed by WoC and CI (Table 5).
Table 2 Number of Identified Papers in the Journal Databases

\begin{tabular}{llll}
\hline Database & No of search hits & $\begin{array}{l}\text { No of potentially relevant } \\
\text { papers (full texts analysed) }\end{array}$ & $\begin{array}{l}\text { No of relevant papers } \\
\text { (in-depth literature nalysis) }\end{array}$ \\
\hline ACM & 7 & 2 & 11 \\
EBSCO & 3 & 0 & \\
Emerald & 4 & 2 & \\
Google Scholar & 377 & 67 & \\
IEEE & 32 & 17 & \\
Sage & 1 & 1 & \\
ScienceDirect & 20 & 12 & \\
\hline
\end{tabular}


Table 3 Conceptualisation of CK in the literature

\begin{tabular}{|c|c|c|c|}
\hline Reference & Conceptualisation & Focus / Context & Research Object \\
\hline \multicolumn{4}{|c|}{ Articles that define crowd knowledge explicitly } \\
\hline Kern (2013) & $\begin{array}{l}\text { "Crowd knowledge: development of knowledge assets or } \\
\text { information resources from a distributed pool of } \\
\text { contributors." }\end{array}$ & $\begin{array}{l}\text { Quality management in } \\
\text { crowdsourcing (cloud labour } \\
\text { markets) }\end{array}$ & $\begin{array}{l}\text { Quality measure for resulting } \\
\text { documents is provided }\end{array}$ \\
\hline $\begin{array}{l}\text { Pawlowski } \\
\quad \text { et al. (2014) }\end{array}$ & $\begin{array}{l}\text { "Crowd knowledge refers to processes, activities and } \\
\text { resources that are created and deployed by a large - } \\
\text { often organisation-independent - user base." }\end{array}$ & Social knowledge environments & Unspecific (research note) \\
\hline \multicolumn{4}{|c|}{ Articles that use crowd knowledge implicitly } \\
\hline $\begin{array}{l}\text { Kwon et al. } \\
\quad(2018)\end{array}$ & $\begin{array}{l}\text { "Crowd knowledge is an imprecisely defined term. In this } \\
\text { paper, it is treated as an extension of collective } \\
\text { intelligence, which is a shared or group intelligence } \\
\text { acquired from various sources such as collaboration, } \\
\text { collective efforts, competition among many individuals } \\
\text { and machines. It is used to make appropriate decisions } \\
\text { in many contexts." }\end{array}$ & Smart cities, health environments & $\begin{array}{l}\text { Classify patients' health based on } \\
\text { multiple sources }\end{array}$ \\
\hline $\begin{array}{l}\text { Brynjolfsson } \\
\quad \text { et al. (2016) }\end{array}$ & $\begin{array}{l}\text { "[.. .] an online game environment is an effective setting } \\
\text { for capturing CK and may be used to elicit reliable } \\
\text { information without any supplementary verification of } \\
\text { users' answers." }\end{array}$ & $\begin{array}{l}\text { Online games are used to } \\
\text { order } / \mathrm{match} / \text { sort elements }\end{array}$ & Online word association game task \\
\hline $\begin{array}{l}\text { de Souza, } \\
\text { Campos, and } \\
\text { de Maia } \\
(2014 a)\end{array}$ & $\begin{array}{l}\text { "In SO [StackOverflow.com], developers post questions } \\
\text { related to a programming topic, and other members of } \\
\text { the site can provide answers to help them. The } \\
\text { information available on this type of service is also } \\
\text { known as 'CK' and currently is one important trend in } \\
\text { supporting activities related to software development } \\
\text { and maintenance." }\end{array}$ & $\begin{array}{l}\text { CK in software development } \\
\text { primarily evolves around } \\
\text { Q\&A forums (stack overflow) }\end{array}$ & $\begin{array}{l}\text { Discussions and sources around a } \\
\text { specific question }\end{array}$ \\
\hline $\begin{array}{l}\text { Erickson et al. } \\
\text { (2012) }\end{array}$ & $\begin{array}{l}\text { "The crowd is also used to advance understanding by } \\
\text { capturing and aggregating distributed knowledge. In } \\
\text { these instances, organisations may either create a } \\
\text { centralised repository of knowledge for use by } \\
\text { employees or customers, or integrate CK into products } \\
\text { to improve performance (e.g. as a source of training } \\
\text { data to improve algorithms)." }\end{array}$ & Organisational CK & $\begin{array}{l}\text { Centralised repositories such as } \\
\text { forums/wikis where specific articles } \\
\text { are maintained }\end{array}$ \\
\hline $\begin{array}{l}\text { Herzog and } \\
\quad \text { Claunch } \\
\text { (1997) }\end{array}$ & $\begin{array}{l}\text { "[Crowd knowledge can be seen] as the squares for the } \\
\text { quilt. Once stitched together, they provide a cohesive } \\
\text { and productive whole. Collectively, all of the } \\
\text { contributions of information from citizens on a subject } \\
\text { conveys a voice of a crowd." }\end{array}$ & $\begin{array}{l}\text { Generic with a tendency towards } \\
\text { social groups/citizens/politics }\end{array}$ & $\begin{array}{l}\text { The "voice of the crowd" which } \\
\text { presents a collaboratively reached } \\
\text { consensus/an aligned agreement. }\end{array}$ \\
\hline $\begin{array}{l}\text { Minguillón and } \\
\text { Conesa } \\
\text { (2011) }\end{array}$ & $\begin{array}{l}\text { "[.. .] the use of CK in order to promote homogeneity on } \\
\text { the tags users use in a non-intrusive way, as well as } \\
\text { allowing learners to organize their own resources ac- } \\
\text { cording to their own criteria but taking advantage of the } \\
\text { institutional repository." }\end{array}$ & $\begin{array}{l}\text { Learning resources in } \\
\text { organisations }\end{array}$ & $\begin{array}{l}\text { The learning resources which are } \\
\text { tagged and thereby classified, } \\
\text { allowing advanced searches/filters }\end{array}$ \\
\hline $\begin{array}{l}\text { Schlagwein } \\
\text { and } \mathrm{Hu} \\
(2016)\end{array}$ & $\begin{array}{l}\text { "Furthermore, some participants described internal social } \\
\text { media as inherently being able to generate a 'pool of } \\
\text { CK [that] formalises the content' (participant 5, product } \\
\text { manager). That is, knowledge that would not normally } \\
\text { be stored in formal knowledge management systems } \\
\text { becomes articulated in discussions and hence becomes } \\
\text { explicit and searchable." }\end{array}$ & Organisational CK & Forum/articles/posts \\
\hline $\begin{array}{l}\text { Shieh et al. } \\
\text { (2010) }\end{array}$ & $\begin{array}{l}\text { "Crowd knowledge [is] embedded in user-intensive social } \\
\text { media such as Wikipedia." }\end{array}$ & Generic & Forum/articles/posts \\
\hline $\begin{array}{l}\text { Shirazi et al. } \\
\text { (2010) }\end{array}$ & $\begin{array}{l}\text { "(Then, when a user who runs the 'Automatic Profile } \\
\text { Change' application enters the cinema his mobile } \\
\text { phone's profile can be automatically switched to a silent } \\
\text { profile.) This makes the mobile phone semi-intelligent } \\
\text { by just applying common CK." }\end{array}$ & Technical (semi-automated) CK & Context-dependent profiles \\
\hline
\end{tabular}

The definition of Pawlowski et al. (2014) is based on Yang et al. (2008). However, we did not include this reference, as it addresses knowledge markets and not $\mathrm{CK}$. 
Table 4 Characteristics and related manifestations

\begin{tabular}{lll}
\hline Characteristic & Manifestation \\
\hline Participation (section 3.3.1) & Creator & Contributor \\
& Consumer & Citizen, user, developer \\
Context (section 3.3.2) & Technological & Social media, in products, semi-intelligent \\
& Environment & Organisational, social \\
Purpose (section 3.3.3) & Objective & Gain value, advance understanding, enable accessibility of mobile \\
& context data via web services, [knowledge] becomes explicit and searchable \\
& Target group & Social media user, product users, readers of journalism, readers of Q\&A, employees, customers \\
Process (section 3.3.4) & Creation & Becomes articulated in discussions, accumulates distributed knowledge, aggregate \\
& Storage & In products, embedded in (internal) social media system, centralised repository \\
& Provision & (Institutional/centralised) repository, information available on this type of service [StackOverflow]
\end{tabular}

We conclude that CS has the highest similarity with $\mathrm{CK}$, so explicating distinctive $\mathrm{CK}$ and $\mathrm{CS}$ features will be the focus of the following analyses. However, other constructs will still be mentioned, in order to highlight core differences.

Following Tatarkiewicz (2012), the elements that are suited for distinguishing $\mathrm{CK}$ from the other concepts are then identified as differentiation criteria, as they are necessary to define CK. Thereafter, the elements are brought together to form a preliminary definition. In the following, the extracted characteristics and related manifestations of $\mathrm{CK}$, listed in Table 4, are discussed to clarify their origin and contribution to the integrated definition, as well as their eligibility as differentiation criteria.

\subsubsection{Participation}

Participation is a fundamental part of CK (Table 4), and the crowd's involvement is a core element in some definitions. Most commonly, the generic term 'user' is mentioned (e.g., Brynjolfsson et al., 2016; Minguillón \& Conesa, 2011). Perspectives on the user's role vary, from a single person switching the profile on his mobile phone (Shirazi et al., 2010), to an anonymous user-base that actively creates content (Pawlowski et al., 2014). In some articles, to elucidate the application context or highlight certain skills, the terms 'citizen' (Herzog \& Claunch, 1997) or 'developer' (de Souza, Campos, \& de Maia, 2014a) are used. Besides the personal attributes of participants, how they participate is a differentiation that can be derived by comparing 'consumer(s), ' who consume CK, to 'contributor(s)' (Kern, 2013), who create it.
It is not surprising that the identified elements, such as the differentiation between consumers and contributors (Kleemann et al., 2008), are in line with similar research. Therefore, participation is a crucial characteristic in defining $\mathrm{CK}$, albeit neither participation in general nor specific types are suitable differentiation criteria. We focus in our conceptualisation in particular on the participation of the crowd and separate this aspect from the target group as part of our objective (section 3.3.3), as the target group could also be a specific individual or an organisation.

\subsubsection{Context}

Few abstract definitions exist, but they all include the application context (Table 4). In existing definitions, two contextdimensions are detected: 'technological' and 'environmental'. While the environmental dimension corresponds to the understanding of context in knowledge science, the technological dimension is rooted in technical aspects of information systems research.

In more tech-savvy articles, the CK system and its functions are described. Shieh et al. (2010) regard social media as a breeding ground for $\mathrm{CK}$ and explicitly name Wikipedia. Furthermore, Erickson et al. (2012) describe CK as an encapsulated artefact that can be integrated into products, while Shirazi et al. (2010) use the current state of connected devices to form a situational CK snapshot that synchronises all devices and lets, for example, mobile phones become 'semi-intelligent' by automatically turning silent when entering a cinema.
Table 5 Lucene similarity scores for relevant concepts

\begin{tabular}{llll}
\hline & Crowdsourcing & Wisdom of Crowds & Collective Intelligence \\
\hline Lucene Score & $30 \%$ & $23 \%$ & $21 \%$ \\
\#Mentions & 36 & 31 & 15 \\
\hline
\end{tabular}


Howe introduced CS as "the act of a company or institution taking a function once performed by employees and outsourcing it" (Howe, 2006). In this definition, the 'organisational' environment is evident and remained unchanged in all ensuing definitions (Estellés-Arolas \& González-Ladrón-de-Guevara, 2012). For CK, an organisational environment is one of two tendencies. Finding the right crowd that matches organisational needs is the desire of Erickson et al. (2012), whilst Schlagwein and $\mathrm{Hu}$ (2016) propose creating CK from discussions between employees and customers on social media. The frequent mention of social media elicits 'social' as a second tendency. While it is used often by organisations, CK is also used in social, nonwork-related environments, However, most related platforms are hybrid forms; StackOverflow, for instance, provides hobby and professional programmers with technical insights (de Souza, Campos, \& Maia, 2014b), tags and social bookmarks that help individuals and organisations organise their resources or identify knowledge gaps (Minguillón \& Conesa, 2011).

Context can be used as differentiation criteria. For CS, technology always refers to the medium internet, and CK is also associated with a technology. In contrast, the $\mathrm{WoC}$ and $\mathrm{CI}$ concepts do not refer to technology at all; instead, an organisational environment is assumed. Although Zhao and Zhu (2014) observed that CS is predicted to go beyond the business world, all of their non-business application examples are still hybrid forms. Collective intelligence has no environmental border or focus.

\subsubsection{Purpose}

It is possible to argue that in a deterministic world, every action has a reason. However, in relation to $\mathrm{CK}$, the purpose relates to the specific knowledge artefact and the intended use in a given context. Gaining value, or advancing understanding, predominantly targets organisational purposes (Erickson et al., 2012). More specific purposes are the implementation of CK to make existing knowledge explicit and thereby searchable (Schlagwein \& Hu, 2016), or using it in combination with the accessibility of mobile context data via web services (Shirazi et al., 2010). Moreover, open Q\&A systems, like StackOverflow, or organisation-independent citizen journalism (Kern, 2013) are social purposes.

While the objective describes what $\mathrm{CK}$ is used for, in some definitions a target group is specified, describing by whom CK is used. These target groups vary in specificity, ranging from customers (Erickson et al., 2012) to social media users (Schlagwein \& Hu, 2016). Purpose seems not to be a suitable differentiation criterion, as all concepts state a purpose, albeit in more or less detail (Table 4). CS and WoC aim to generate value, and CI wants to improve understanding. While one could argue that the target characteristic is most dominant in
CK definitions, a strong overlap with context characteristics must be acknowledged, thus rejecting purpose as a unique characteristic.

\subsubsection{Process}

There are three CK process steps: creation, storage and provision. Aggregating the distributed knowledge that a group of individuals possesses is the primary method for CK creation, highlighting its collaborative nature, but besides specific creation, CK can emerge as a side product from discussions on social media, where knowledge inevitably has to be articulated (Schlagwein \& Hu, 2016). In the end, it yields an artefact, which can be a knowledge asset or information resource (Kern, 2013), formal content (Schlagwein \& Hu, 2016), processes, activities and resources (Pawlowski et al., 2014) and discussions or a combination of a Q\&A (Kern, 2013). Furthermore, it can be implemented in products, either static, for example as a source of training data to improve algorithms (Erickson et al., 2012), or dynamic, like the intelligent mobile phone (Shirazi et al., 2010). Discussions are automatically stored on the platform on which they operate (Schlagwein \& $\mathrm{Hu}, 2016$; Shieh et al., 2010). Centralised repositories are used, if CK is intentionally gathered, and often strongly linked to an environmental context (Erickson et al., 2012; Minguillón \& Conesa, 2011). Moreover, the type of storage influences how CK can be accessed. Repositories (Erickson et al., 2012; Minguillón \& Conesa, 2011), social media (Schlagwein \& Hu, 2016; Shieh et al., 2010) and Q\&A platforms (de Souza, Campos, \& Maia, 2014b) can be accessed by all or restricted to a selected group. Either way, the artefact must be deliberately retrieved and used.

A process description is common among all concepts, but the level of specificity is especially high for CK definitions and elements, and therefore they qualify as differentiation criteria. For CS, only the solution / problem solving process is analysed (Estellés-Arolas \& González-Ladrón-de-Guevara, 2012). In his concept of WoC, Surowiecki (2005) talks about aggregation, and Tapscott (2011) lists sharing as the cornerstone of CI. Crowdsourcing is often referred to as method employed to create solutions, but it also includes applications where an open call is issued and participants contribute individually, resulting in independent responses (Estellés-Arolas \& González-Ladrón-de-Guevara, 2012). This collective effort is important, as participants should at least be able to give feedback to an author, and while CS is "a type of participative online activity" (Estellés-Arolas \& González-Ladrón-deGuevara, 2012), CK is a tangible artefact. These are pieces of knowledge that can be used in a specific context. The existence of an artefact proves the requirement for storage and provision, which can - but does not need to - exist for other crowd-based concepts, as they might produce volatile results. 
Based on the previous analysis, combining the identified characteristics, a holistic definition is created that covers all variations of $\mathrm{CK}$ while distinguishing it from hitherto often synonymously used concepts and terms:

"Crowd knowledge is a collaborative aggregation of context-dependent information contributed and used by participants that is stored in an artefact and provided to fulfil a purpose."

\subsection{Stage 4: Demonstration of the Applicability of the Conceptual CK Definition}

To ensure the applicability of our CK definition, it is demonstrated in a practical setting. As the Lucene score indicated that the distinction between CS and CK is most relevant (section 3.3), we follow Vukovic and Bartolini (2010), who evaluate their CS taxonomy by using identified features to analyse related platforms. To that end, we verify our definition by analysing if the distinctive characteristics are suited for discriminating between cases involving $\mathrm{CK}$ and those that do not do so.

For the demonstration of applicability, we follow EstellésArolas and González-Ladrón-de-Guevara (2012) to examine the usefulness of the CK definition based on knowledge artefacts. In this procedure, a set of web platforms is compared with the criteria in the definition. Our suggested CK definition contains the following aspects, based on the characteristics determined in Table 4 and the previous sections 3.2 and 3.3.

1. A group of participators ${ }^{1}$ (the crowd) exists

2. A context ${ }^{2}$ in which the knowledge is used

3. A purpose for

a. what is achieved (objective)

b. by whom the knowledge is applied (target group)

4. The knowledge creation and provision includes:

a. a collaborative creation process

b. the knowledge storage in $\mathrm{CK}$ artefacts

c. the knowledge provision (sharing).

Our goal is to clarify how well we can distinguish web applications that implement CK from those that use other crowd-based concepts or none at all. Estellés-Arolas and González-Ladrón-de-Guevara (2012) used a set of 11 websites to evaluate their crowdsourcing definition. Even

\footnotetext{
${ }^{1}$ As explained in section 3.3.1, we focus under participator on the crowd and address the specific target group of the knowledge artefact as part of the purpose.

${ }^{2}$ We do not consider the technological context here, as all platforms are webbased and therefore this criterion is fulfilled for all entities in our sample.
}

though CK can exist outside of the internet, it is highly relevant for digitised crowd-based initiatives, so we adapted the Estellés-Arolas and González-Ladrón-de-Guevara (2012) sample. However, we replaced Lánzanos with Kickstarter, as the functionally is similar, albeit the latter is currently the most successful crowdfunding platform (Frydrych et al., 2014). Furthermore, we excluded Fiat Mio, because it was a onetime initiative in 2010, and del.icio.us, as the website has been acquired by pinboard.in and no longer exists. However, we did not include pinboard.in, as it is a bookmark management application without any relation to CK. Instead, we added social media (Facebook, Twitter and Reddit), crowdfinding (Crowdfind) and a crowdvoting platform to the sample (Rotten tomato), thereby allowing us to cover a broader range of crowd-related platforms. We use the term 'platform' instead of 'website', as some require more than an actual web presence to operate. For instance, crowdsearching relies on GPS data from mobile devices. Two researchers evaluated the knowledge artefacts on each platform separately, based on the criteria outlined above. One of them was not involved in the previous coding that led to the differential criteria in section 3.1, to avoid related biases. The classification resulted in an inter-coder reliability of $92.86 \%$. The remaining differences were discussed until both researchers agreed on the classification. Table 6 contains the platforms, the knowledge artefact and the characteristics of the CK definition.

We begin in alphabetical order with Crowdfind. On this platform, the knowledge artefact is the search result for a physical object. A crowd provides the technical infrastructure to track an item via their mobile devices, and a context for the knowledge artefact exists, as the search is related to a specific object (e.g. a product in a warehouse). Furthermore, a clear objective is given, and the target group for the search and the results exists. The search results are stored on the platform, and the platform shares the results with the initiators. When the service was launched, these were mostly individuals, but then Crowdfind pivoted to business customers for facility management. In this context, we regard the organisation as a crowd - and therefore the tracking results are used by a crowd. However, the question arises as to whether the sharing of GPS data can be considered collaborative knowledge creation. Based on the revised knowledge pyramid (section 2.1), we conclude that this is only data, as the crowd does not know the context, the platform only uses the technical infrastructure, and there is no conscious cognitive collaboration. Therefore, we conclude that Crowdfind is not CK.

Facebook and Twitter represent social media platforms. The knowledge artefact of these platforms is the post or tweet, and a crowd of users and content providers exists. While posts and tweets are highly heterogeneous, most content relates to a specific context. The content also has an objective (e.g. to inform or amuse) and targets a particular group of users, but 


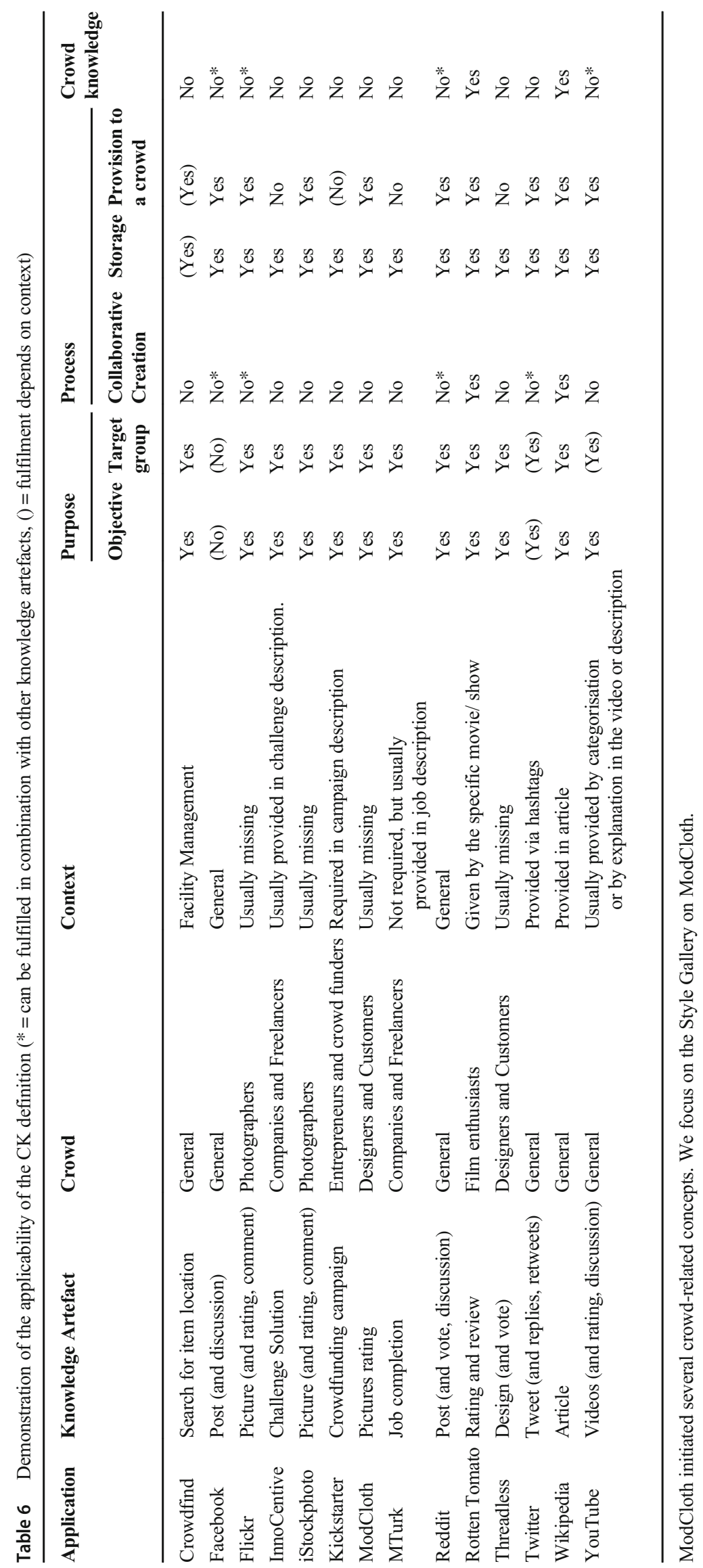


objectives and target groups are clearer in relation to a tweet, while the objective and target group of a Facebook post might be less obvious. However, while the platform shares and provides knowledge, its creation is not collaborative, in that each post or tweet comes from one individual. Therefore, social media is not crowd knowledge. This classification changes when we also consider the additional comments, replies and possible retweets on Twitter. This in turn allows for collaborative knowledge creation, as a particular tweet or post could be enriched by a discussion, thereby allowing new perspectives, more content or suggested solutions. Thus, we acknowledge that the combination of multiple knowledge artefacts (e.g. post and discussion) can create a CK knowledge artefact. However, as this is not necessarily the case, we classify the knowledge artefacts accordingly.

InnoCentive is a web-based ideas competition, and the knowledge artefact is the solution to a challenge that someone has released on the platform. The challenge is given to the crowd, which in turn tries to solve the problem (solvers). A context is given, as the entity that posts the challenge (seeker) provides an overview explaining the problem. The knowledge artefact is comparable with Mechanical Turks such as MTurk that allow job requestors to share a job on the platform. The knowledge artefact in this example is a job, and MTurk workers can accept the job based on its description to explain the context. The target group is the requestor (MTurk) or Seeker (InnoCentive) who states the objective. However, on both platforms, the corresponding process to create the knowledge artefact is not collaborative; furthermore, on both platforms, members of the crowd cannot see contributions made by others and complete the job/challenge on their own. In addition, it is questionable if the jobs on MTurk represent knowledge. For instance, the completion of a survey would occur at the data level in the revised knowledge pyramid (section 2.1) and cannot be classified as CK. On both platforms, the solutions are temporarily stored on the platform and shared only with the target group. However, as knowledge generation is not collaborative, ideas competitions and Mechanical Turks cannot be classified as CK.

The platform iStockphoto provides a collection of usergenerated images. In this case, the image is the knowledge artefact. While it is possible to argue that a target group of individuals interested in the images exists, and that images have an objective (e.g. to entertain), they do not necessarily provide a context. We further argue that knowledge creation can be collaborative, as many individuals could share pictures of an event (e.g. a specific protest or the inauguration of the Pope) and others can reflect on them and share their opinions, using comments. While this scenario is possible, it is not common on iStockphoto and not the main intention. Consequently, we do not classify the images on iStockphoto as CK, due to the lack of content and the missing collaborative knowledge creation.
Kickstarter is a crowdsourcing platform. The related knowledge artefact is the crowdfunding campaign. Context and purpose are provided in the campaign description; however, funders support campaigns monetarily and not necessarily with knowledge. While the support of the crowd could indicate market success, the contribution of the individual cannot be considered part of collaborative knowledge creation, as it occurs only at the data level of the revised knowledge pyramid (section 2.1).

ModCloth is a fashion website that conducts crowd voting initiatives. We look at the knowledge artefact of the image rating. While a crowd exists that rates the images, a specific context is not given. The objective of the rating is clear, and a target group exists (individuals interested in the images). The images and the rating are shared with a crowd but discarded once the voting has ended. In addition, it appears questionable whether aggregated voting based on numerical values or the selection between different alternatives can be considered collaborative knowledge creation. This also raises the question as to whether a general election is $\mathrm{CK}$, as a crowd selects a specific party from different alternatives. From our perspective, knowledge creation requires more than this, as the target group should be able to reflect on the generated knowledge. The same classification applies to Threadless. On this platform, artists can make design suggestions, i.e. knowledge artefacts, for fashion products. The crowd evaluates the suggestions, and the designs winning the highest share of the vote are manufactured. However, similar to ModCloth, this does not constitute collaborative creation of shareable knowledge. Furthermore, we also analysed Reddit and Rotten Tomato. Reddit combines social media with web content rating, and members can vote content up and down. If we consider the rating of web content as a knowledge artefact, then the simple up and down voting system does not fulfil the collaborative knowledge creation in our CK definition. A combination of knowledge artefacts (e.g. post, vote and discussion) can yield $\mathrm{CK}$, but this is not necessarily the case. In contrast, Rotten Tomato aggregates movie and TV show reviews. This includes reviews from critics and an audience score. In this context, the ratings are not just a numerical average; instead, all textual reviews are provided as well, which allows someone to read several reviews in order to gain a better understanding of the content. We argue that this falls under our definition of $\mathrm{CK}$, as the knowledge artefact is collaboratively created. It is similar to the collaboration of journal reviewers assessing a research paper, because even though they do not directly communicate and exchange their opinion, they still create collective knowledge in relation to the paper. In other words, collaborative knowledge creation can be direct or indirect, and the latter does not require communication between the knowledge creators. Therefore, we classify the reviews on Rotten Tomato as CK, but not the selected knowledge artefacts on Reddit or ModCloth. 
Furthermore, we include Wikipedia to validate our definition. Here, the respective article is the knowledge artefact, and it is created collaboratively by a crowd that can make suggestions, reflect on them and then alter the article. Articles also address the context, as they clarify and restrict it, for example by providing different articles for entities used in different contexts. The purpose is given, and the information is stored and publicly shared. As a result, Wikipedia articles are CK.

Finally, we look at YouTube, where a video is the knowledge artefact and is created by a user and not a crowd, albeit the crowd can comment on the video. Videos commonly have a purpose (e.g. to entertain), create some kind of context (e.g. the situation in the video) and are stored and shared on the platform. Again, the question depends on the collaborative knowledge creation. The video is not $\mathrm{CK}$ per se, but in combination with the comments a CK knowledge artefact can be created. For instance, a comment could be used to provide further information about the context in which the video was recorded or explain a phenomena shown in the video. Similar to social media, we do not classify YouTube videos as CK, but we nevertheless acknowledge that different knowledge artefacts such as videos and related comments can be combined to create $\mathrm{CK}$.

The analysis shows that most platforms associated with crowdsourcing by Estellés-Arolas and González-Ladrón-deGuevara (2012) cannot be classified as CK. Two criteria in our definition seem particularly relevant in this context, namely the lack of context and missing collaboration in the knowledge development process. The results reveal that the degree of collaboration that justifies $\mathrm{CK}$ is debatable, as it can depend on the specific knowledge artefact; however, we conclude that our definition is suitable to describe the phenomenon.

\section{$4 \mathrm{CK}$ and its Impact on Knowledge Management}

In this section, we discuss the relationship with and impact of $\mathrm{CK}$ on theories in knowledge management. We build on the
$\mathrm{KM}$ concepts introduced in section 2 and our suggested definition of CK (section 3), beginning with a summary of the differences between $\mathrm{CK}$ and similar concepts. This is followed by a discussion of the $\mathrm{CK}$ artefact, and an outline of the differences in the knowledge creation process and knowledge flow compared to established knowledge management concepts.

\subsection{Summary of the Comparison of CK with Related Concepts}

The crowd concepts introduced herein are classified based on the conceptual definition of CK. As shown in Table 7, not all identified CK characteristics are specified by the other concepts, which shows that different concepts focus on different areas of application.

Comparing the previously introduced crowd concepts, using CK dimensions, highlights the different focal points of other concepts especially related to the process. CK necessitates and evolves around its instantiation in an artefact, whilst CS intends to provide a solution to a specific problem. WoC emphasises the anonymity of participants and aligns with the political, socio-cultural context in which it was developed. Lastly, CI's focus is quality assurance resulting from a stringent peer-review approach. As the other concepts do not consider the holistic knowledge (artefact) lifecycle, they do not specify all related steps (create, store, provide). Furthermore, the aspects are not necessarily distinct, but they do describe the focus; for example, crowdsourcing can be achieved with anonymous contributions but must be aimed at solving a problem/finding a solution. The missing target (group) is best explained by not considering context transitions and the initial purpose/objective directly implicating a suitable target (group), i.e. crowdsourcing targets a crowd that is knowledgeable and can solve a given problem.

\subsection{The Uniqueness of the CK Artefact}

In section 3, we showed that the conceptualisation of CK requires a tangible and explicit instantiation in an artefact.

Table 7 Comparison of the crowd-based concepts from a CK perspective

\begin{tabular}{|c|c|c|c|c|c|}
\hline \multicolumn{2}{|c|}{ Characteristic } & CK & CS & WoC & CI \\
\hline \multicolumn{2}{|c|}{ Participation } & Contributor \& Consumer & Contributor \& Consumer & Contributor \& Consumer & Contributor \& Consumer \\
\hline \multirow[t]{2}{*}{ Context } & Technological & (Usually) Internet-based & Internet-based & Not specified & Not specified \\
\hline & Environment & Heterogeneous & Heterogeneous & Organisational & Not specified \\
\hline \multirow[t]{2}{*}{ Purpose } & Objective & $\begin{array}{l}\text { Heterogeneous (depends on } \\
\text { CK artefact and context) }\end{array}$ & Value creation & Value creation & Understanding \\
\hline & Target (group) & Heterogeneous & Not specified & Not specified & Not specified \\
\hline \multirow[t]{3}{*}{ Process } & create & Collaboratively & Not specified & Anonymously & Peer-reviewed \\
\hline & store & (Usually) via a platform & Not specified & Not specified & Not specified \\
\hline & provide & (Usually) via a platform & Focus on problem solution & Not specified & Not specified \\
\hline
\end{tabular}


For instance, in relation to social media, we additionally observed that different information, such as a post in combination with a discussion and voting, can create a CK artefact. Therefore, we conclude that the specification of CK artefacts is highly relevant for CK. While the theoretical need for CK artefacts is not yet elicited in the literature, practical implementations and conceptualisations from knowledge management exist.

Butler et al. (2008) adopted the knowledge asset (KA) concept and suggested a schema to design knowledge systems, whereby the artefact is understood as the whole information system (Conway \& Sligar, 2002), in order to depict knowledge instantiation. Knowledge assets reside within the information systems of the researched entities, for instance a university R\&D team and a government department, thus providing context. Table 8 compares the KA concept with the CK artefact.

The primary conceptual difference between KA and CK artefacts is that KA focuses on the generation of knowledge inside a static organisational context. In this context, CS processes could be implemented in order to either generate or integrate knowledge, which allows for organisation-specific customisations but abandons true interoperability and the transition of knowledge among contexts. In contrast, $\mathrm{CK}$ artefacts can be created based on different information (e.g. a video and a related discussion) and transferred in another context. For instance, an article on Wikipedia might be a used as a CK artefact for the creation of another article on a similar topic. However, we note that judgment must be exercised that is not required for KA to put information into context and thereby elevate it to knowledge. CK artefacts lack a static environment that carries tacit knowledge and allows socialisation; thus, codifying elements that support the judgment and transitions between contexts are essential. Another difference between the concepts is complementary KA, as knowledge is an intermediate good that needs to be packaged into goods and services to yield value (Tsoukas \& Vladimirou, 2001). This necessity does not exist in relation to the $\mathrm{CK}$ artefact, since the technology (e.g. the internet) allows the provision and sharing of $\mathrm{CK}$, and there is no requirement to repackage knowledge; instead, many platforms (e.g. Rotten Tomato or Wikipedia) provide $\mathrm{CK}$ for free. This is made possible because the crowd creates the knowledge, and the platform provides the infrastructure through which to share the content. In addition, we note that KA is more formal and requires a description, while $\mathrm{CK}$ artefacts are dynamic and can be composed by combining different information. Therefore, CK artefacts depend in particular on the context and the process. Finally, the creators differ, in that KA is created by a specific group of authors in the organisation, while CK artefacts are created by a crowd where anonymity is often possible. The crowd is also dynamic, as members can join and leave this cohort at any time. We therefore conclude that KAs are specific, static and organisational, while CK artefacts are general, dynamic and context-dependent. In addition, we observe that the process involved in using $\mathrm{CK}$ artefact differs from the process to use KA. In the following section, we investigate this aspect further.

\subsection{A Process-Oriented Perspective on CK}

In the previous sections, we determined that the characteristics context and process are suitable differentiation criteria (section 3.4). In knowledge-related information systems, our proposed definition supports process-oriented knowledge management, as it fosters the provision of a context, aids navigation through prospective systems and thus supports their design and implementation (Maier \& Remus, 2002). While process orientation bridges the gap between human- and technology-oriented knowledge management (Maier \& Remus, 2003), the focal point of CK artefacts shifts toward technology orientation.

Following Tsoukas and Vladimirou's (2001) understanding of Davenport (1998), "knowledge is both an outcome and a process for incorporating." Given the technical orientation, CK therefore contains the technological instantiation, the CK artefact, as an outcome and a process implementation, where technical solutions support required processes. In most cases, CS provides well-suited methods for process implementation. The relevance of context has already been acknowledged in Jennex and Bartczak's (2013) revised knowledge pyramid, which relates the impact of social networks onto organisational learning (section 2.1).
Table 8 Matching KA elements with CKA characteristics

\begin{tabular}{lll}
\hline & Crowd Knowledge Artefact & Knowledge Asset (KA) \\
\hline Application area & Heterogeneous context & Organisational domain \\
Purpose & Objective & Objective \\
& Target group & End-user \\
Utilization & Usually via technology & Complementary KA \\
Specification & Depends on context & Description \\
Knowledge Creators & (Dynamic) crowd & (Static) Author(s) \\
\hline
\end{tabular}


In the case of distributed systems with dynamic crowds, both the context from which the processed information originates and the context in which the information is supposed to be processed to fulfil a purpose need to be known. Tsoukas and Vladimirou (2001) regard organisational knowledge as "the capability members of an organisation have developed to draw distinctions in the process of carrying out their [organisational] work, in particular concrete [organisational] contexts, by enacting sets of generalisations whose application depends on historically evolved collective understandings and experiences [within the organisation]". Obviously, organisation pervades this concept. When dissociating from the organisational setting and conceptualising $\mathrm{CK}$, this vacancy must be filled, so a CK artefact must integrate and provide its context; otherwise, it would merely constitute crowd information, not crowd knowledge. At the very least, when transferred from the environment in which it was created and then integrated elsewhere, the failure to provide a context would avert the adequate judgment and therefore the adaptation of the CK artefact, hence, contradict interoperability and pervasive knowledge development. Pursuing this holistic view, our new CK concept extends Jennex and Bartczak's (2013) line of thought beyond the uni-directional knowledge development in organisational boundaries and describes the traversing of knowledge independent of the environment, thereby fostering interoperability of any kind of KM system.

Polanyi (2005) and Wittgenstein and Anscombe (1958) established that abstract formalisms are not self-sustaining but need a manifestation for effective deployment, which forms from collective significance. For communication, transfer or further development, this manifestation must be explicated to be accessible, and in the last instance, it is an individual process. Therefore, a CK artefact constitutes the current state of the collective knowledge, formed through knowledge processes and influenced by multiple participants. Starting from the abstract concept, an infrastructure and a context allow for the application of generic and domain-specific processes to instantiate ultimately in tangible knowledge.

Using the explicated characteristics, a general framework that emphasises specific $\mathrm{CK}$ characteristics can be depicted, as shown in the upper-left part of Fig. 2. It supports the understanding of $\mathrm{CK}$ by visualising the previously formulated holistic CK definition. Furthermore, researchers and practitioners can use it to position their project and identify points of contact.

Generally, there must be an encapsulating context that defines the used technology and the environment, whereby a crowd exists, containing mere knowledge consumers and contributors that (1) collaboratively create CK artefacts (Fig. 2). For collaborative creation, CS is a frequently but not exclusively used method. The artefact is (2) stored and (3) provided, and a primary purpose has bearing on its creation, storage and provision. The crowd is usually dynamic, as it does not have a specific number of participants, and every individual can join the crowd and contribute (e.g. in the creation of an article on Wikipedia). This is different compared to other concepts such as knowledge assets, which are created and used by a static group of members of an organisation (section 4.2). Figure 2 highlights the dynamic of the crowd by indicating individuals in, outside and on the edge of the crowd. In addition, CK artefacts can be used in different contexts; Erickson et al. (2012), for instance, suggested that CK could be used for training purposes, which in turn further increases the dynamic of CK, as it can change its purpose over time. The upper-right
Fig. 2 Crowd knowledge process and flow

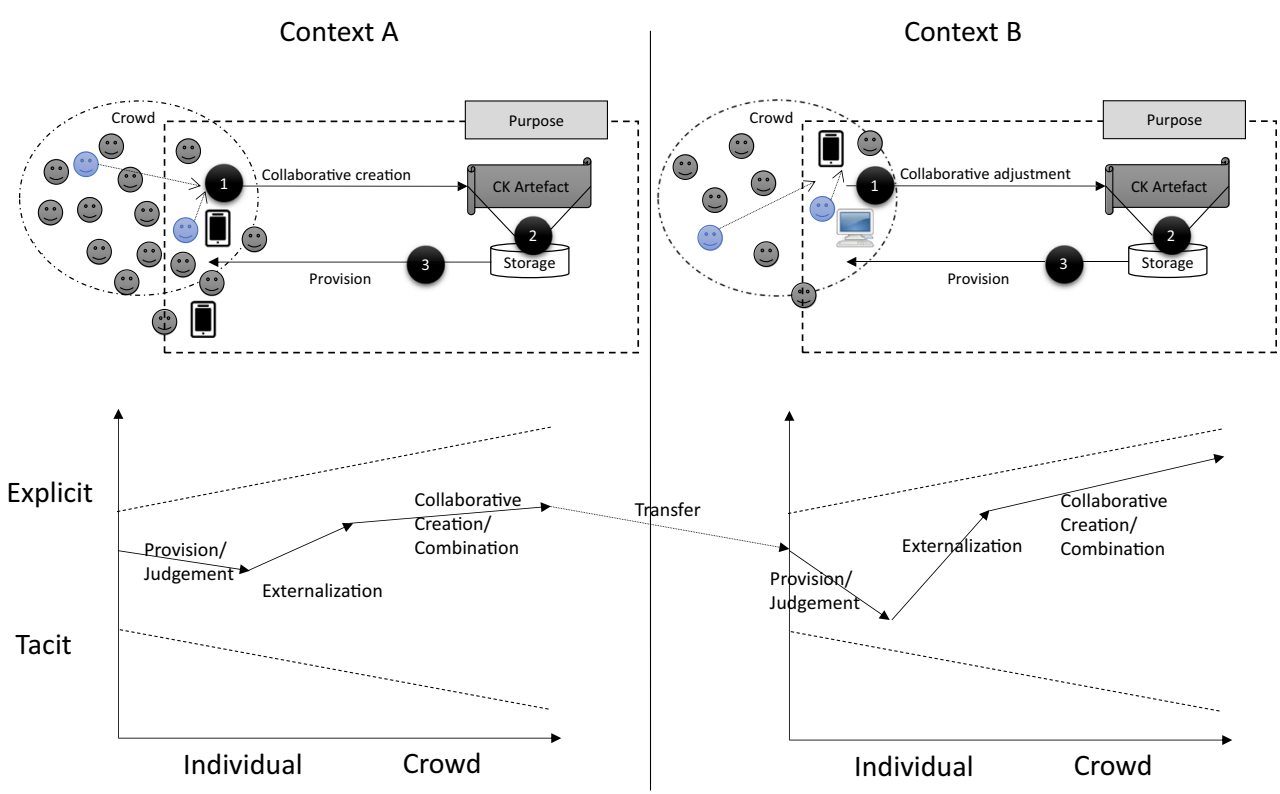


part of Fig. 2 illustrates how a CK artefact is used in another context. In this scenario, it does not have to be created again, but it may be adjusted according to the needs of the audience. However, the second and third steps remain the same, albeit the technical infrastructure might change (as depicted by the different devises used by the crowd).

\subsection{CK Knowledge Flow}

The epistemological differentiation of knowledge into tacit and explicit elements (Polanyi, 2005) is a major aspect of Nonaka's (1994) dynamic theory of organisational knowledge creation (section 2.1). Ontological is the second dimension and depicts the level of social interaction. In his model, the flow of knowledge in organisations is outlined, and four phases describe how it traverses between tacit and explicit knowledge. First, socialisation describes how members of a group interact and thereby tacit knowledge converges within the group. Second, combination describes the use of social processes to exchange - and thus combine - different bodies of explicit knowledge. Third, externalisation, and fourth, internalisation, are complementary processes of mutual interaction which describe the conversion from tacit to explicit knowledge and vice versa. The conversion in both dimensions (epistemological and ontological) supports the idea of an organisational memory wherein all knowledge of an organisation is stored (section 2.1). However, in this understanding, the organisation provides a static context in which to embed tacit knowledge and an environment where social interaction - and hence socialisation - occurs naturally (Nonaka, 1994). Lacking this physical and mental environment, CK must rely on codifiable elements.

The following example illustrates the knowledge transfer between contexts (Fig. 2). A movie on Rotten Tomato is reviewed by an individual, who watches and interprets it in the current political and economic context and publishes their opinion on the platform, thereby collaborating in the review process of the movie and creating CK. However, several years later, it might be that another crowd watches the movie and reads the reviews. While the movie and the related CK artefact have not changed, it might be that they are now considered in a different (historical) context and therefore the crowd will interpret the $\mathrm{CK}$ artefact according to this new context.

The lower-left part of Fig. 2 depicts the related flow of CK. Without an organisational context of Nonaka's (1994) original model, the tangible, explicit CK artefact marks the starting point. It must be judged in the context it is used for, thereby traversing into the tacit knowledge of the judging participant. At this point, the participant has learned something, since converting explicit into tacit knowledge adjusts the body of tacit knowledge. Furthermore, by externalising the adjusted knowledge, the participant can contribute, and by reacting to contributions and combining these with his own adjustments as well as with others, collaborative creation occurs. As the judgment, and therefore the contributed adjustments, relates to a context, this process elevates the explicated knowledge for this context. When the crowd changes or the CK artefact is transitioned into another context (Xu et al., 2019), i.e. by using knowledge from a hobby discussion board in an organisational project (Wang et al., 2015), parts of the explicit knowledge can become incongruous to the new context. Consequently, the judgement, externalisation and collaborative creation process must start again in the changed context.

\section{Conclusion}

The term CK gained popularity alongside the rise of CS, but suffered from a clear conceptual definition, leading to confusion in its application. To unfurl the confusion, we synthesised existing definitions, and derived a comprehensive definition to provide a fundamental and exhaustive understanding of CK. Then, we demonstrated the applicability of the definition using a sample of heterogeneous online platforms in the CS space. The results suggest clear differences between CK and other related concepts including CS (Howe, 2006), WoC (Surowiecki, 2005), CI (Lévy, 1997). In the following, we will elaborate the theoretical implications for the wider IS community, the managerial implications, as well as future research opportunities.

\subsection{Theoretical Implications}

Driven by increased penetration of digital technology and the corresponding organisational and socio-cultural shifts, crowdbased methods massively impact the digital environment. However, previous research in Information Systems on crowd knowledge is often dated and does not adequately adjust to current distinctions. Recent studies, for example, elaborated the characteristics of crowdsourcing processes but neglected distinct properties of crowd knowledge artefacts.

We considered and adopted philosophical (Polanyi, 2005; Wittgenstein \& Anscombe, 1958) and organisational knowledge (Lehner \& Maier, 2000) conceptualisations in order to align with the requirements of dispersed crowds in digital environments, such as context dependence and the necessity for actual instantiation of crowd knowledge artefacts. A structured process to develop conceptual definitions is followed in order to substantiate the hitherto theoretical claim. Relevant crowd knowledge definitions are extracted from the literature and coded to explicate characteristics, of which participation, context and process qualify as differentiation criteria (Tatarkiewicz, 2012), as they are suited to distinguish crowd knowledge from similar concepts. A holistic crowd knowledge definition is postulated, combining eight characteristics of CK: a crowd, a technological context, an environmental 
context, an objective, a target (group) and a process for collaborative creation, storage and provision. In addition, our conceptual definition was critically discussed by considering established theories such as knowledge assets and knowledge systems. Acknowledging the importance of the artefact, a comparison of an existing knowledge asset concept (Butler et al., 2008) with the contributed crowd knowledge artefact resulted in matching elements in both cases. To demonstrate the applicability (research object 2), the conceptual definition was used in relation to different knowledge artefacts on crowd-based platforms. The results confirmed the suitability of the formulated conceptualisation of $\mathrm{CK}$ and show that the context and the process constitute differentiation criteria and therefore capture the essence of CK.

The theoretical contribution of this study is that we provide a CK definition and disentangle crowd knowledge and other crowd-based approaches as a set of distinct concepts. Currently, research that integrates a crowd-based approach uses one of the existing crowdsourcing taxonomies (e.g., Estellés-Arolas \& González-Ladrón-de-Guevara, 2012) to classify the utilised approach. The identified differentiation criteria provide a straightforward approach to distinct CK from CS. Additionally, this shows how the contributed concept aids understanding of actual implementations. Following the postulated conceptualisation allows researchers to better understand the characteristics of the artefact being analysed, thus obviating forced classification attempts that do not fit well. Moreover, our CK definition enables more precision in the academic discussion and related research initiatives. This makes it easier for the Information Systems community to distinguish research on crowd-based concepts such as CS (Howe, 2006), WoC (Surowiecki, 2005), CI (Lévy, 1997) based on their distinctive characteristics. Additionally, ensuring a common understanding makes research initiatives more transparent and comparable.

A further theoretical contribution of our study is that it emphasises the relevance of the knowledge artefact in the CK process and flow. The discussion in the demonstration of the definition's applicability indicates that CK can often be achieved when several knowledge artefacts that contain explicated knowledge are combined, such as a post, vote, and the related discussion on Reddit. However, the interpretation of the knowledge artefacts is always depending on the given context and therefore subject to change. In our discussion, we adapt the established knowledge flow concept from Nonaka (1994) to depict possible context transitions of crowd knowledge artefacts. The integration and adaptation of CK in knowledge management concepts allows us to consider the involved parties and their interaction. We describe how knowledge artefacts flow between different contexts and develop along the epistemological and ontological dimension. The results suggest an adjusted knowledge flow based on judgement, externalisation and collaboration that turns tacit knowledge into explicit knowledge. This improves the understanding of existing crowdbased implementations and supports the prudent design of future systems. Our results suggest that CK should be treated as an individual concept and that it does not fit the processoriented definition(s) of CS. Our contribution provides a deeper understanding of CK in the Information Systems community and could inspire future research to expand and challenge our ideas (see section 5.3).

\subsection{Practical Implications}

While the theoretical focus of our paper prevails, it also offers managerial implications for the development of CK systems. Firstly, our definition provides clear guidelines how CK can be created by incorporating the eight $\mathrm{CK}$ characteristics in a given system. Without a shared understanding of these attributes, participants might perceive the system differently, leading to confusion. As Wessel et al. (2017) noted, participants may talk past each other, causing societal-level information pathologies. We introduce in section 3.4 a checklist approach to classify online platforms based on our definition. Practitioners could implement a similar approach to classify the knowledge within their organisation based on our definition. This would allow them to determine missing or unspecific aspects such as environmental context, purpose, or target group. Secondly, our results suggest that CK often arises when multiple knowledge artefacts are combined. Therefore, practitioners should aim to combine multiple knowledge artefacts in a CK system to increase the generation of CK. For instance, allowing the sharing of different media (e.g., photos and videos) in combination with discussion boards is particularly suitable for CK environments. Thirdly, our processoriented perspective on $\mathrm{CK}$ suggests that $\mathrm{CK}$ changes in relation to the given context. This creates practical challenges and opportunities for the storage of CK. In this context, the eight characteristics included in our $\mathrm{CK}$ definition can be used to ensure that even when combining distributed systems all aspects of CK are captured (e.g., the crowd that created the knowledge, the technological context, the objective, the target group, and the storage of the knowledge artefacts).

\subsection{Future Research}

Our CK definition could be a foundation for future research initiatives. Firstly, we demonstrated the applicability of our CK definition only with selected online platforms. While we tried to cover a wide range of CS platforms, the selection is still limited. Further research is required in order to explore how the definition can be used in other settings (e.g., for CK within organizations). Secondly, we derive the CK process and flow by adapting established knowledge management theories such as Nonaka's (1994). Future research should 
verify these theoretical considerations empirically. In-depth case studies would be particularly useful in this context to understand how CK is created and how it turns from tacit knowledge into explicit knowledge. Eventually, the introduction of knowledge artefacts provides a bridge to design science (Peffers et al., 2007). Thus, future research could adopt established guidelines from design science to support the development of knowledge artefacts and the implementation of CK systems. For instance, existing guidelines for conceptual modelling (Lukyanenko et al., 2017) could be aligned with identified attributes, to ensure that resulting artefacts meet $\mathrm{CK}$ requirements.

\section{Appendix A. Lucene similarity score}

In this Appendix, we describe how the Lucene similarity score works, why it is advantageous to use it to determine similarity and which similarity scores we calculated.

We use Lucene similarity scoring, which is a state-of-theart method combining multiple measures to calculate a similarity score (McCandless et al., 2010). It ranks results according to the similarity between a search query and the documents matching this query. In simple terms, it determines how important a word is to a document in a repository of documents, by setting the frequency of the term in a given document in relation to its rareness therein (McCandless et al., 2010). The actual implementation is complex and includes multiple steps and factors, combining a "Boolean model of Information Retrieval with Vector Space Model of Information Retrieval" (Lucence, 2017).

At first, documents (d) that contain terms (t) relating to the search query (q) are identified. Thereafter, the query and the documents are transformed to weighted vectors, making it possible to calculate these vectors' dot product and use it as score (Manning, 2008):

Lucene Score $(q, d)=$

$\operatorname{coord}(q, d) x$ queryNorm $x \sum_{t \text { in } q}\left(t f(t, d) x\right.$ idf $(t)^{2} x$ weight $(t) x$ norm $\left.(t, d)\right)$

where coord() calculates how many query terms are found in the document, queryNorm() normalises scores for comparison, $\mathrm{tf}()$ calculates a term's frequency in a document, idf() is the inversed document frequency, weight() is the impact of a given term, and can be used to boost a specific term, and norm() encapsulates some boost and length factors.

A major advantage of the Lucene score is that the included normalisations can handle significant differences in the analysed repository, regarding the number of documents containing the search terms, and still produce comparable results. Thereby, we can ensure that the similarity score is not distorted by CS's popularity.

Funding Open Access funding enabled and organized by Projekt DEAL.

Open Access This article is licensed under a Creative Commons Attribution 4.0 International License, which permits use, sharing, adaptation, distribution and reproduction in any medium or format, as long as you give appropriate credit to the original author(s) and the source, provide a link to the Creative Commons licence, and indicate if changes were made. The images or other third party material in this article are included in the article's Creative Commons licence, unless indicated otherwise in a credit line to the material. If material is not included in the article's Creative Commons licence and your intended use is not permitted by statutory regulation or exceeds the permitted use, you will need to obtain permission directly from the copyright holder. To view a copy of this licence, visit http://creativecommons.org/licenses/by/4.0/.

\section{References}

AIS (2011). Senior Scholars' Basket of Journals. https://aisnet.org/page/ SeniorScholarBasket.

Ayaburi, E. W., Lee, J., \& Maasberg, M. (2020). Understanding crowdsourcing contest fitness strategic decision factors and performance: An expectation-confirmation theory perspective. Information System Frontiers, 22, 1227-1240.

Bates, M. (2005). Information and knowledge: An evolutionary framework forinformation science. Information Research. Information Research: An International Electronic Journal, 10(4), Paper1.

Bell, D. (1976). The coming of the post-industrial society. The Educational Forum, 40(4), 574-579.

Bloor, D. (1983). Wittgenstein: A social theory of knowledge. Columbia University Press.

Bonabeau, E. (2009). Decisions 2.0: The power of collective intelligence. MIT Sloan Management Review, 50(2), 45-52.

Brynjolfsson, E., Geva, T., \& Reichman, S. (2016). Crowd-squared: Amplifying the predictive power of search trend data. MIS Quarterly, 40(4), 941-961.

Butler, T., Feller, J., Pope, A., Emerson, B., \& Murphy, C. (2008). Designing a core IT artefact for knowledge management systems using participatory action research in a government and a nongovernment organisation. Journal of Strategic Information Systems, 17(4), 249-267.

Conway, S., \& Sligar, C. (2002). Unlocking knowledge assets. Microsoft Press.

Davenport, T. H. (1998). Working knowledge : How organizations manage what they know. Harvard Business School Press.

de Souza, L. B. L., Campos, E. C., \& de Maia, AM. (2014a). On the Extraction of Cookbooks for APIs from the Crowd Knowledge. (pp. 21-30): IEEE.

de Souza, L. B. L., Campos, E. C., \& Maia, M. D. A. (2014b). Ranking crowd knowledge to assist software development. (pp. 72-82): ACM.

Erickson, L., Petrick, I., \& Trauth, E. (2012) Hanging with the right crowd: Matching crowdsourcing need to crowd characteristics. In Proceedings of the Eighteenth Americas Conference on Information Systems, Seattle, Washington.

Estellés-Arolas, E., \& González-Ladrón-de-Guevara, F. (2012). Towards an integrated crowdsourcing definition. Journal of Information Science, 38(2), 189-200. https://doi.org/10.1177/ 0165551512437638 .

Frické, M. (2009). The knowledge pyramid: A critique of the DIKW hierarchy. Journal of Information Science, 35(2), 131-142. 
Frydrych, D., Bock, A. J., Kinder, T., \& Koeck, B. (2014). Exploring entrepreneurial legitimacy in reward-based crowdfunding. Venture Capital, 16(3), 247-269.

Galton, F. (1907). Vox populi (the wisdom of crowds). Nature, 75(7), $450-451$.

Garvin, A. P., \& Berkman, R. (1995). The art of being well-informed: What you need to know to gain the winning edge in business (2nd ed.): Avery.

Gold, A. H., Malhotra, A., \& Segars, A. H. (2001). Knowledge management: An organizational capabilities perspective. Journal of Management Information Systems, 18(1), 185-214.

Gong, Y. (2017). Estimating participants for knowledge-intensive tasks in a network of crowdsourcing marketplaces. Information Systems Frontiers, 19(2), 301-319.

Hedberg, B. (1981). How organizations learn and unlearn. In P. C. Nystrom \& W. H. Starbuck (Eds.), Handbook of organizational design (pp. 3-27). Oxford.

Herzog, R. J., \& Claunch, R. G. (1997). Stories citizens tell and how administrators use types of knowledge. Public Administration Review, 57(5), 374-379.

Hota, C., Upadhyaya, S., \& Al-Karaki, J. N. (2015). Advances in secure knowledge management in the big data era. Information Systems Frontiers, 17(5), 983-986.

Howe, J. (2006). The rise of crowdsourcing. Wired Magazine, 14(6), 1-4.

Jennex, M., \& Bartczak, S. (2013). A revised knowledge pyramid. International Journal of Knowledge Management (IJKM), 9(3), 19-30.

Jyh-Ren, S., Ching-Yung, L., Shun-Xuan, W., Yung-Huan, H., \& JaLing, W. (2010). Incorporating multi-partite networks and expertise to construct related-term graphs. (pp. 535-542): IEEE.

Kern, R. (2013). Dynamic quality management for cloud labor services. Springer.

Kleemann, F., Voß, G., \& Rieder, K. (2008). Un(der) paid innovators: The commercial utilization of consumer work through crowdsourcing. Science, Technology \& Innovation Studies, 4(1), $5-26$.

Kwon, O., Kim, Y., Lee, N., \& Jung, Y. (2018). When Collective Knowledge Meets Crowd Knowledge in a Smart City: A Prediction Method Combining Open Data Keyword Analysis and Case-Based Reasoning. Journal of Healthcare Engineering, 15.

Le Bon, G. (1897). The crowd: A study of the popular mind. Fischer.

Lehner, F., \& Maier, R. (2000). How can organizational memory theories contribute to organizational memory systems? Information Systems Frontiers, 2(3), 277-298.

Lévy, P. (1997). Collective intelligence : mankind's emerging world in cyberspace. Plenum Trade.

Lucence (2017). Similarity (lucence 5.5.4 api). http://lucene.apache.org/ core/5_5_4/core/org/apache/lucene/search/similarities/ TFIDFSimilarity.html.

Lukyanenko, R., Wiersma, Y., Huber, B., Parsons, J., Wachinger, G., \& Meldt, R. (2017). Representing crowd knowledge: Guidelines for conceptual modeling of user-generated content. Journal of the Association for Information Systems, 18(4), 297-339.

Maier, R., \& Remus, U. (2002). Defining process-oriented knowledge management strategies. Knowledge and Process Management, 9(2), $103-118$.
Maier, R., \& Remus, U. (2003). Implementing process-oriented knowledge management strategies. Journal of Knowledge Management, $7(4), 62-74$.

Malone, T., Laubacher, R., \& Dellarocas, C. (2009). Harnessing crowds: Mapping the genome of collective intelligence. Technology, 1.

Manning, C. D. (2008). Introduction to information retrieval. Cambridge University Press.

McCandless, M., Hatcher, E., \& Gospodnetić, O. (2010). Lucene in action (2nd ed.). Greenwich, Conn.: Manning publications.

McIlraith, S. A., Son, T. C., \& Zeng, H. (2001). Semantic web services. IEEE Intelligent Systems, 16(2), 46-53.

Minguillón, J., \& Conesa, J. (2011) From institutional repositories to personal collections of learning resources. In The Personal Learning Environments Conference.

Nonaka, I. (1994). A dynamic theory of organizational knowledge creation. Organization Science, 5(1), 14-37.

Pawlowski, J., Bick, M., Peinl, R., Thalmann, S., Maier, R., Hetmank, L., et al. (2014). Social knowledge environments. Business \& Information Systems Engineering, 6(2), 81-88.

Peffers, K., Tuunanen, T., Rothenberger, M. A., \& Chatterjee, S. (2007). A design science research methodology for information systems research. Journal of Management Information Systems, 24(3), 4577.

Piccoli, G., \& Ives, B. (2005). IT-dependent strategic initiatives and sustained competitive advantage: A review and synthesis of the literature. MIS Quarterly, 29(4), 747-776.

Polanyi, M. (2005). Personal knowledge : Towards a post-critical philosophy. Routledge.

Prpić, J., \& Shukla, P. (2014). The contours of crowd capability. (pp. 3461-3470): IEEE.

Rowley, J. (2007). The wisdom hierarchy: representations of the DIKW hierarchy. Journal of Information Science, 33(2), 163-180. https:// doi.org/10.1177/0165551506070706.

Saxton, G. D., Oh, O., \& Kishore, R. (2013). Rules of crowdsourcing: Models, issues, and Systems of Control. Information Systems Management, 30(1), 2-20.

Schlagwein, D., \& Hu, M. (2016). How and why organisations use social media: Five use types and their relation to absorptive capacity. Journal of Information Technology, 32(2).

Shieh, J.-R., Lin, C.-Y., Wang, S.-X., Hsieh, Y.-H., \& Wu, J.-L. (2010). Incorporating multi-partite networks and expertise to construct related-term graphs. (pp. 535-542): IEEE.

Shirazi, A. S., Winkler, C., \& Schmidt, A. (2010). SENSE-SATION: An extensible platform for integration of phones into the web. (pp. 1-8): IEEE.

Simmons, J. P., Nelson, L. D., Galak, J., \& Frederick, S. (2011). Intuitive biases in choice versus estimation: Implications for the wisdom of crowds. Journal of Consumer Research, 38(1), 1-15.

Surowiecki, J. (2005). The wisdom of crowds: Anchor books.

Tapscott, W. A. D. D. (2011). Wikinomics how mass collaboration changes everything. Atlantic Books Ltd..

Tatarkiewicz, W. (2012). A history of six ideas: An essay in aesthetics (Vol. 5): Springer science \& business media.

Tsoukas, H., \& Vladimirou, E. (2001). What is organizational knowledge? Journal of Management Studies, 38(7), 973-993.

Vukovic, M., \& Bartolini, C. (2010). Towards a research agenda for enterprise crowdsourcing. (Vol. 6415, pp. 425-434). 
Wang, G., Liu, X., Wang, J., Zhang, M., \& Fan, W. (2015). Examining micro-level knowledge sharing discussions in online communities. Information Systems Frontiers, 17(6), 1227-1238.

Webster, J., \& Watson, R. (2002). Analyzing the past to prepare for the future: Writing a literature review. MIS quarterly, 26(2), XIII-XXIII.

Wessel, L., Gersch, M., \& Harlo, E. (2017). Talking past each other. Business \& Information Systems Engineering, 59(1), 23-40.

Wiig, K. M. (1997). Knowledge management: An introduction and perspective. Journal of Knowledge Management, 1(1), 6-14.

Wittgenstein, L., \& Anscombe, G. E. M. (1958). Philosophical investigations (2nd ed.). Blackwell.

Xu, Y., Wang, L., Xu, B., Jiang, W., Deng, C., Ji, F., \& Xu, X. (2019). An information integration and transmission model of multi-source data for product quality and safety. Information Systems Frontiers, 21(1), 191-212.

Yang, J., Adamic, L., \& Ackerman, M. (2008). Crowdsourcing and knowledge sharing: Strategic user behavior on taskcn. (pp. 246255): ACM.

Zhao, Y., \& Zhu, Q. (2014). Evaluation on crowdsourcing research: Current status and future direction. Information Systems Frontiers, 16(3), 417-434.

Publisher's Note Springer Nature remains neutral with regard to jurisdictional claims in published maps and institutional affiliations.

Till Blesik earned his doctoral thesis from ESCP Business School Berlin where he worked as a research assistant at the Chair of Business
Information Systems. His research interests include crowd knowledge, blockchain, technology adoption, and machine learning. He published his work in renowned international journals and peer-reviewed conferences. He is founder and owner of netvigation, a consulting firm for technology and software solutions, and works as a data solution architect.

Markus Bick (Dr., University of Duisburg-Essen) is full Professor and holds the Chair of Business Information Systems at ESCP Business School Berlin. He was the local academic director of ESCP's bachelor in management in Berlin. His current research interests include blockchain, digital transformation including digital competencies and digital maturity models as well as global knowledge management. He published his work in renowned international journals (Journal of Business Logistics, Electronic Markets, Information \& Management, Business Information Systems Engineering, Decision Support Systems, International Journal of Information Management or Information Systems Management) and is an Associate Editor of Electronics Market and a Senior Editor of Information Systems Management.

Tyge-F. Kummer is an Associate Professor at the Queensland University of Technology (QUT). His research interests comprise in particular judgement and decision making, accounting information systems, business process management, and fraud detection and prevention. His research has been published in journals including the Journal of the Association of Information Systems, Decision Support Systems, International Journal of Information Management, Information \& Management, Business \& Information Systems Engineering, as well as in proceedings of internationally recognised conferences. 